\title{
Purification of Model Dairy Wastewaters by Ozone, Fenton Pre-treatment and Membrane Filtration
}

\author{
Mihály Zakar1,2, Dániel Imre Farkas², Erika Hanczné-Lakatos, Gábor Keszthelyi-Szabó², \\ Zsuzsanna László2,3* \\ ${ }^{1}$ Institute of Food Sciences, Faculty of Agricultural and Food Sciences, Széchenyi István University, H-9200 Mosonmagyaróvár, \\ Lucsony út 15-17., Hungary \\ 2 Department of Process Engineering, Faculty of Engineering, University of Szeged, H-6725 Szeged, Moszkvai krt. 9, Hungary \\ ${ }^{3}$ Institute of Environmental Science and Technology, Faculty of Agricultural and Food Sciences, University of Szeged, \\ H-6720 Szeged, Tisza Lajos krt. 132, Hungary \\ * Corresponding author, e-mail: zsizsu@sol.cc.u-szeged.hu
}

Received: 30 September 2019, Accepted: 17 February 2020, Published online: 15 May 2020

\begin{abstract}
This study aimed to investigate the effect of ozone and Fenton-reaction as a pre-treatment before ultrafiltration of model dairy waste waters containing sodium caseinate. Filtration resistances and pollutant retentions were determined and compared. It was found, that both pre-treatment increased the retention, achieving almost $100 \%$ pollutant elimination efficiency after short term pre-oxidation. The effect of Fe-ion concentration on Fenton pretreatment efficiency also was examined, and it was found that higher concentration resulted in decreased filtration resistances, revealing that coagulation-flocculation effect of reactants has dominant role in the protein separation efficiency. The presence of lactose also affects the pollutant removal efficiency, it promotes fouling in presence of Fenton reagents.
\end{abstract}

\section{Keywords}

membrane separation, fouling, dairy waste water, ozone, Fenton reaction

\section{Introduction}

The dairy industry generates the large volume of wastewater (approximately $2.5 \mathrm{~L} /$ liter [1] of processed milk and varies between 0.2 to $10 \mathrm{~L}$ of effluent per liter of processed milk) due to large water consumption [2], originated from washing and cleaning operations during the technology. Dairy wastewaters can be characterized by high biological and chemical oxygen demand, due to their high organic content, mainly carbohydrates, proteins and fats originating from milk. These effluents have the following average characteristics: Biochemical Oxygen Demand (BOD), with an average ranging from 1,000 to $3,000 \mathrm{mg} / \mathrm{L}$ in the untreated effluent, Chemical Oxygen Demand (COD) ranging from 2,000 to $5,000 \mathrm{mg} / \mathrm{L}$, Total Suspended Solids (TSS) at 400-1,000 (mg/L), total dissolved solids (TDS): phosphorus (10-30 mg/L), and nitrogen (about $6 \%$ of the BOD level). Levels of potential contaminants in dairy wastewaters typically exceed the levels considered hazardous for domestic wastewaters. They may contain microorganisms including pathogens, from contaminated materials or production processes, and they often generate odors and, in some cases, dusts, which also need to be controlled [3].

The conventional treatments of these effluents include the use of primary physical treatments to remove solids, oils and fats, secondary biological treatment to remove organic matter and nutrients. Several problems of conventional treatments have been reported, such as high production of scum, low sludge settle ability, low flexibility of the technology, difficulties in removal of nutrients (nitrogen and phosphorus) and problems in the oil and fat degradation [4]. Because of the reduction in water availability and the increase in water treatment costs, several researches aim to develop new technologies for wastewater treatment, not only aiming to meet the standards but also to obtain treated effluents feasible for reuse. Considering these, membrane separation techniques seem to be promising processes for the treatment of dairy industrial wastewaters [5]. 
Earlier works proved that an appropriate retention can be achieved by membrane filtration and permeates can be reused. However, membrane fouling is a limiting factor in these processes. Proteins, thus the milk proteins are known to be severe foulants for the existing membrane materials [6-8]. Various matters may cause fouling; dairy wastewaters contain the organic compounds of milk like caseins. Caseins generally have an open structure, and most of them are present in milk as Casein Micelles (CMs) [9]; at native $\mathrm{pH}$ and room temperature, about $95 \%$ of caseins are associated as colloidal assemblies of micelles with the size of 50-300 nm in diameter. Unlike caseins, whey proteins generally have tertiary and quaternary structures, which can influence concentration polarization and pore fouling of the membrane [10, 11].

There are several methods to overcome the fouling issue, e.g. use of low fouling membranes, application of physical methods, like ultrasound or vibration [12] or chemical pre-treatments (e.g. coagulation-flocculation, flotation ozonation or adsorption [13]. Among chemical pre-treatments the Advanced Oxidation Processes (AOPs), like Fenton reaction [14] and ozone, are widely used in the fields of water and wastewater treatments [15-17] are known for their capability to mineralize a wide range of organic compounds. AOPs also have some other effects on the filtration procedure, e.g. the micro-flocculation effect [18], and it may play a significant role in increased elimination efficiency and causing a decreased level of irreversible fouling [19] and proved to be efficient in improving flux [20-23]. Beside these the pre-oxidation may improve the biodegradability of the retained pollutants [24], which meets the requirements of circular economy approach.

For purification of real dairy waste waters, it is important to understand the interactions and behaviors between the particles. To date, although there are several works investigated the protein fouling effect, very limited information available about the effect of pre-oxidation on fouling propensity of the membranes during filtration of proteins. Present study aims to investigate the effect of the Fenton reaction and ozone treatment as a pre-treatment of model dairy waste waters containing milk proteins (casein, in the form of sodium caseinate). The object of the work was to determine the main factors and the mechanism of pre-oxidation affecting the filtration resistances and pollutant elimination efficiencies.

\section{Materials and methods}

The model waste water contained $1.2 \mathrm{~g} / \mathrm{L}$ sodium caseinate and in some cases $1.5 \mathrm{~g} / \mathrm{L}$ lactose (pure $99 \%$, VWR International, Hungary). Fenton reaction was carried out in a stirred vessel with 1.5 or $0.75 \mathrm{mmol} / \mathrm{dm}^{3} \mathrm{FeSO}_{4} \times 7 \mathrm{H}_{2} \mathrm{O}$ (pure $99 \%$, VWR International, Hungary) adjusted to $\mathrm{pH} 3$ with $1 \mathrm{M} \mathrm{H}_{2} \mathrm{SO}_{4}$ (pure $96 \%$, Farmitalia Carlo Erba, Italy), and $\mathrm{H}_{2} \mathrm{O}_{2}(30 \%$ ) (pure $99 \%$, VWR International, Hungary) solution. The $\left[\mathrm{H}_{2} \mathrm{O}_{2}\right]$ :[Fe] ratio was $5: 1$ or in some cases $10: 1$ (Fenton (5:1 or 10:1). The initial $\mathrm{H}_{2} \mathrm{O}_{2}$ concentration was equal in all experiments. The treatment was carried out for $0 \mathrm{~min}$, $30 \mathrm{~min}, 60 \mathrm{~min}$ and $90 \mathrm{~min}$, and stopped by adjustment of the $\mathrm{pH}$ to 7 ; the remaining hydrogen peroxide was decomposed by using catalase enzyme. During ozone treatment experiments, ozone-containing gas was bubbled continuously through a batch reactor. The durations of the treatment were 5, 10 and 20 mins; and the flow rate was $1 \mathrm{dm}^{3} \mathrm{~min}^{-1}$. The absorbed ozone concentration was determined by measuring the ozone concentration of the bubbling gas before and after the reactor; the absorbed ozone was $30 \mathrm{~g} / \mathrm{m}^{3}$ in $5 \mathrm{~min}$ utes $35 \mathrm{~g} / \mathrm{m}^{3}$ in 10 minutes and $40 \mathrm{~g} / \mathrm{m}^{3}$ in 20 minutes. The volume of the treated water was $0.4 \mathrm{dm}^{3}$. Ozone was produced from oxygen (Messer, 3.0) with a flow-type ozone generator (Ozomatic Modular 4, Wedeco Ltd., Germany).

The UF experiments were carried out in a batch stirred ultrafiltration cell (Millipore, XFUF04701, USA) with a capacity of $250 \mathrm{~cm}^{3}$, and the filtrations were performed at $0.3 \mathrm{MPa}$ transmembrane pressure and the feed solutions were stirred at $350 \mathrm{rpm}$. For filtration experiments flat-sheet PES membranes (PES10 series, New Logic, USA) with MWCO $10 \mathrm{kDa}$ were used with effective membrane area of $0.00173 \mathrm{~m}^{2}$. The initial feed volume was $250 \mathrm{~cm}^{3}$, the UF experiments were carried out until $200 \mathrm{~cm}^{3}$ of the total sample was filtered, where the volume reduction ratio $\mathrm{VRR}=5$.

Determination of the COD was based on the standard method involving potassium-dichromate oxidation; for the analysis, standard test tubes (Lovibond, EU) were used. The digestions were carried out in a COD digester (Lovibond, ET 108); the COD values were measured with a COD photometer (Lovibond PC-CheckIt). The contact angles and surface free energy was measured by OCA15, Dataphysics, the surface free energies of membranes were calculated by the Owens, Wrndet, Rabel, and Kaelble (OWRK) method, using the OCA15 SCA22 software 
package (1998-2013 Dataphysics Instruments V. 4.4.1 build 1046). Resistance-in-series model was applied to analyze filtration resistances during the ultrafiltration process [25].

\section{Results}

\subsection{Effect of pre-oxidation reactions on sodium caseinate solution}

In preliminary studies the effect of ozone and Fenton reaction on chemical oxygen demand of the model solution containing sodium caseinate was examined. It was found, that the 20 min ozone treatment and 90 min Fenton treatment resulted in only a slight, not significant decrease in COD. As dairy effluents often contain lactose, the effect of presence of lactose on the efficiency of the Fenton reaction also was investigated, but there was not significant change in the COD values during 90 min Fenton treatment of $1.2 \mathrm{~g} / \mathrm{L}$ Na-caseinate and $1.5 \mathrm{~g} / \mathrm{L}$ lactose containing solution.

\subsection{Effect of pre-treatments on filtration parameters}

In the first series of experiments sodium caseinate $(1.2 \mathrm{~g} / \mathrm{L})$ solutions were pre-oxidized with ozone for 5,10 and $20 \mathrm{~min}$, and Fenton reactions for 0, 30, 60 and $90 \mathrm{~min}$ with $5: 1\left[\mathrm{H}_{2} \mathrm{O}_{2}\right]:[\mathrm{Fe}]$ ratio, then filtered. It was found, that ozone treatment increased the filtration resistances, thus decreased the flux. The resistances in series model showed, that during the filtration of sodium caseinate, the irreversible resistances are dominant; the ozone pretreatment could not decrease the irreversible resistance, but increased the reversible resistances (Fig. 1).

Fenton pre-treatment decreased both reversible and irreversible resistances; and this was observed without any oxidation reaction, by merely adding the Fenton reagents. Short term oxidation further decreased the filtration resistances, thus increased the flux, while longer term (90 min) treatment decreased the flux, probably due to degradation of larger molecules, which may cause fouling of the membrane.

Comparison of the COD elimination efficiency of ozone and Fenton pre-treated sodium caseinate solutions by ultrafiltration (Fig. 2 (a) and (b) showed, that the pre-treatment significantly enhanced the elimination efficiency in both cases, almost $100 \%$ protein elimination was achieved after short term ozone-treatment. In case of Fenton reaction, as it was expected, the addition of reagents without any oxidation reaction also increased the elimination efficiency due to the coagulation-flocculation of the reactants. The long term oxidation decreased the retention of organic matter, due to the degradation of large protein molecules to smaller organic molecules, e.g. organic acids. This was

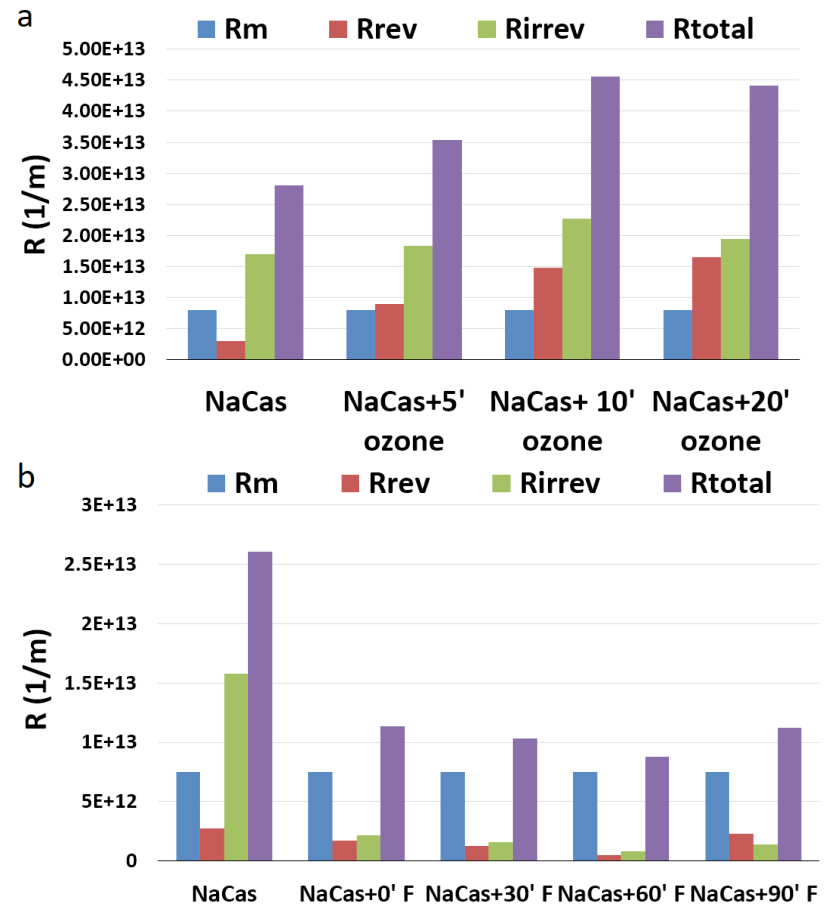

Fig. 1 (a) Fouling resistances of oxidation-pretreated sodium caseinate solutionsin case of ozone treatment; (b) Fouling resistances of oxidation-pretreated sodium caseinate solutions in case of Fenton pretreatment $\left[\mathrm{H}_{2} \mathrm{O}_{2}\right]:[\mathrm{Fe}]=5: 1$

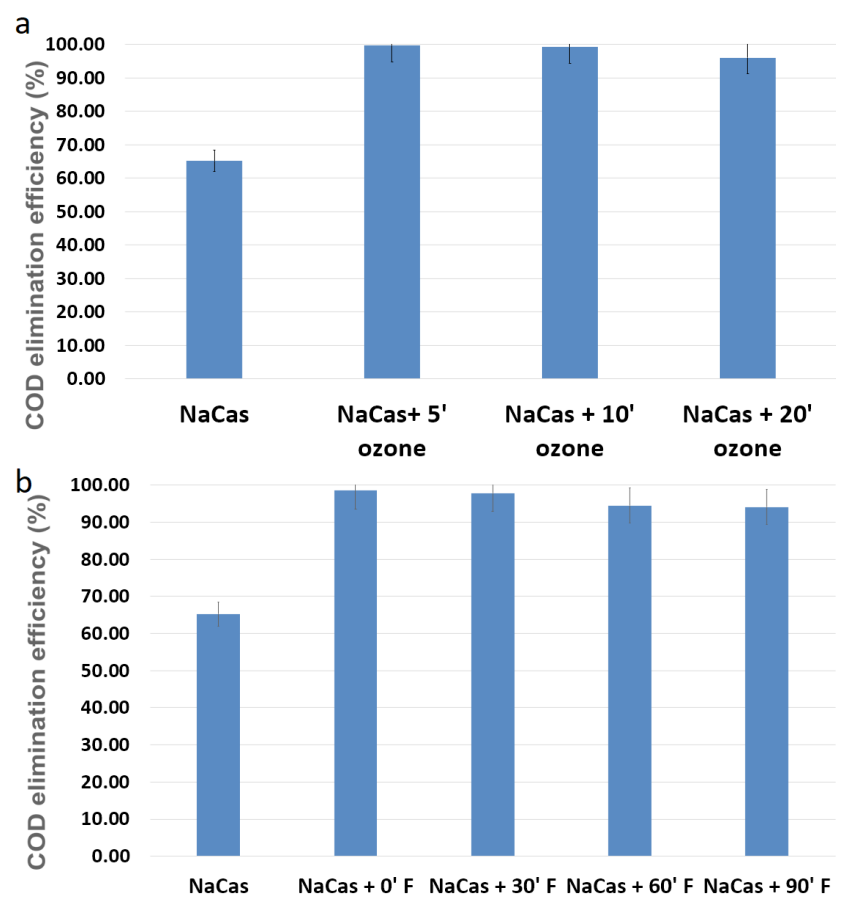

Fig. 2 (a) COD elimination efficiencies of oxidation-pretreated sodium caseinate solutions in case of ozone treatment; (b) COD elimination efficiencies of oxidation-pretreated sodium caseinate solutions in case of Fenton pretreatment $\left[\mathrm{H}_{2} \mathrm{O}_{2}\right]:[\mathrm{Fe}]=5: 1$ 
proved by the decrease of $\mathrm{pH}$ during 5, 10 and $20 \mathrm{~min}$ ozone treatment (from 7 to $6.15,5.29$ and 5.09 respectively), caused by the degradation byproducts.

\subsection{Effect of Fe-ion concentration on filtration parameters}

Our earlier results showed [26] that the fouling propensity of pollutants did not depend on the pretreatment method, but depended on the Oxidation Capacity (OCC). As our recent results bring on the role of coagulation-flocculation effect of Fenton reagents, the effect of Fe-ion concentration without changing hyrogen peroxide concentration also was investigated. Comparing the filtration resistances and retention values after Fenton 5:1 and 10:1 pretreatments, it was found, that the elimination efficiences did not depend significantly on the Fe-ion concentration, but the filtration resistances (Fig. 3.) were found to be higher in case of pre-treatments performed with lower Fe-concentartion. Similarly to the Fenton 5:1 pre-treatment, long term oxidation increased both reversible and irreversible resistances, but instead of irreversible resistance (unlike in untreated solutions) reversible resistances were higher.

\subsection{Effect of lactose on filtration of Fenton pre-treated sodium caseinate solutions}

As dairy waste waters often contain lactose, which may significantly affect the filterability, in the next series of experiments the filtration resistances in presence of lactose were examined (Fig. 4). It was found, that the presence of lactose increased the total resistance of sodium caseinate solution (see Fig. 1 (b)), which could not be decreased by adding Fenton reagents. However, in this case the Fenton reaction had positive effect on resistances, the total resistance decreased due to decreasing the irreversible resistance.

In order to reveal the explanation of the increased fouling

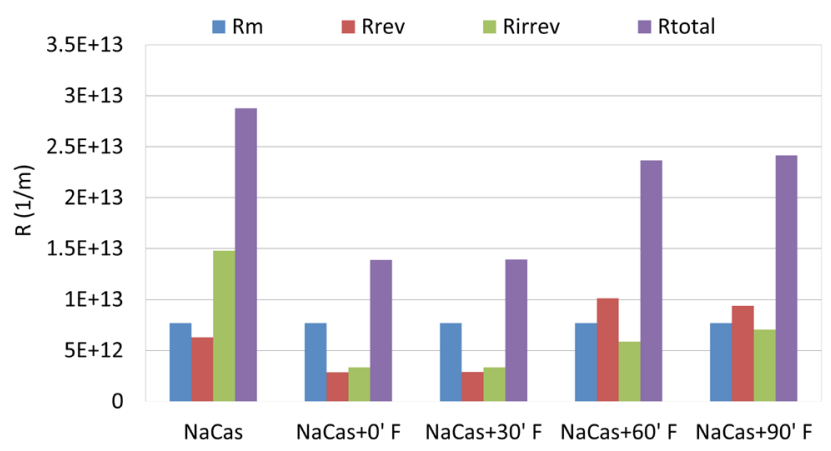

Fig. 3 Filtration resistances of Fenton-pretreated sodium caseinate solutions in case of 10:1 $\left[\mathrm{H}_{2} \mathrm{O}_{2}\right]:[\mathrm{Fe}]$ ratio

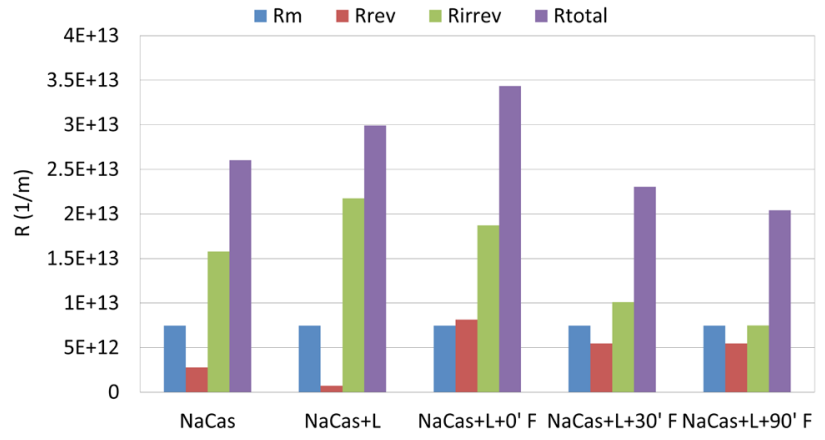

Fig. 4 Fouling resistances of Fenton pre-treated (Fenton 5:1) sodium caseinate and lactose containing solutions

effect of the presence of lactose, the surface free energy values of fouled membranes were compared (Fig. 5). The measurements were carried out at the end of the filtration, after rinsing membranes, thus the surface was covered by the particles caused the irreversible resistance.

Earlier researches showed that surfaces with higher surface free energy are more prone to be fouled [27]. The neat membrane has the highest surface free energy, while the fouled membranes showed lower SFE values.

\section{Discussion}

With shorter ozone pre-treatment (5-10 min) first the microflocculation effect of the ozone prevail, resulting in larger particles, which can get in the membrane pores causing higher filtration resistances (Fig. 1, Fig. 6 (a)), and at the same time high pollutant retention. As we increase the time of the oxidation pre-treatment $(20 \mathrm{~min})$, larger particles degrade to smaller ones, which can go through the membrane. This resulted in decreased purification efficiency (Fig. 2) so as decreased membrane resistances, as the particles no longer stick to the membrane pores. Similar effect can be observed with the Fenton-pre-treatment, because of the coagulation/flocculation effect of the $\mathrm{FeSO}_{4}$ reagent.

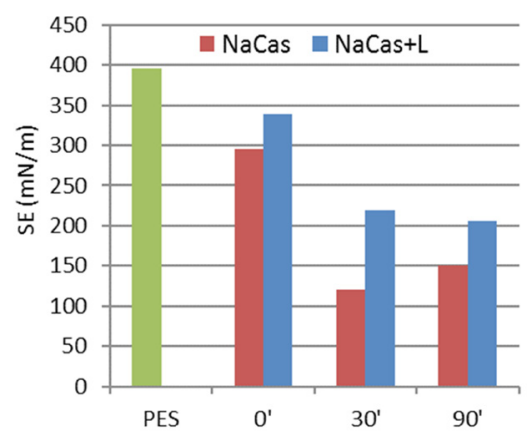

Fig. 5 Surface free energy values of the neat PES membrane and the fouled membranes after filtration of Fenton pretreated solutions (Fenton 5:1) an absence and presence of lactose 


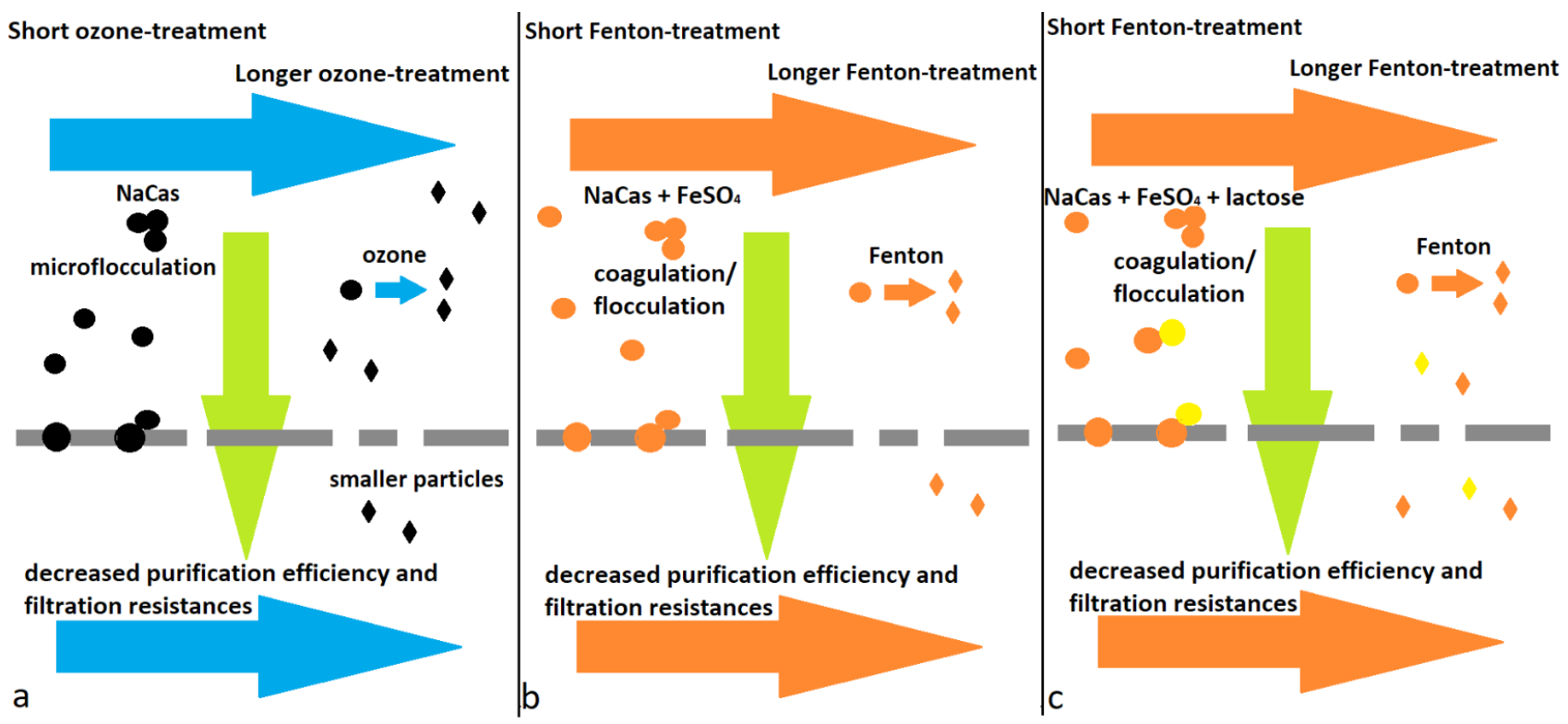

Fig. 6 Effect of the pre-treatments on membrane filtration of model dairy wastewaters I case of (a) short term ozone treatment,

(b) short term Fenton treatment in absence of lactose, (c) short term Fenton treatment in presence of lactose

However, in this case larger precipitated particles were formed, causing lower filtration resistance and higher pollutant retention (Fig. 1, Fig. 6 (b)). As we add the lactose to the model wastewater, without any treatment the irreversible resistance increases (Fig. 4, Fig. 6 (c)), probably due to the changes in the surface charge and thus the size of particles in presence of lactose. As these particles foul the membrane pores, the resistances increases, but as the oxidation effect prevail $(30-90 \mathrm{~min})$ the filtration resistances decreasing so as the purification efficiency due to degradation of the particles (Fig. 4).

\section{Conclusion}

This study aimed to investigate the effect of the Fenton reaction and ozone as a pre-treatment of model dairy waste waters containing sodium caseinate. It was found, that in absence of lactose, addition of Fenton reagents without any oxidation reaction increases the flux, and mitigates fouling; in case of the 30' Fenton pre-treated wastewaters the fluxes at VRR $=5$, in case of 5:1 and 10:1 $\left[\mathrm{H}_{2} \mathrm{O}_{2}\right]:[\mathrm{Fe}]$ ratio were $140 \%$ and $100 \%$ higher respectively, compared to untreated wastewaters. Higher Fe-ion concentration $\left(1.5 \mathrm{mmol} / \mathrm{dm}^{3}, 5: 1\left[\mathrm{H}_{2} \mathrm{O}_{2}\right]:[\mathrm{Fe}]\right.$ ratio) has more favorable effect, proving that the fouling mitigation caused mainly by coagulation-flocculation effect of reagents. On the other hand, in presence of lactose, the oxidation reaction needed to achieve flux increasing. Long term treatment has no positive effect on the fouling mitigation; the formed oxidation by-products may stick to the membrane surface, or got into the pores increasing reversible and irreversible resistances.

Although the ozone as pre-treatment increased the elimination efficiency, it highly increased the filtration resistances so it is not recommended as pre-treatment with this type of wastewater.

On the basis of the surface free energy measurements, it can be assumed, that the solutes (organic compounds and Fenton reagents) easily can be adsorbed to the surface of the neat membrane (which is characterized by high surface free energy), causing irreversible fouling, but after this early stage, the fouling is determined by the interaction of the solute and the adsorbed layer on the membrane surface instead of solute-membrane interactions.

This phenomenon is more expressed in presence of lactose; although the presence of lactose did not change considerably the filterability of sodium caseinate, it can promote fouling in presence of Fenton reagents.

\section{Acknowledgements}

The research was supported by the project TÉT:2017-2.3.7TÉT-IN-2017_00016. The authors are also grateful for the financial support provided by EFOP-3.6.2-16-20017-00010 (RING-2017) ÚNKP-17-II-SZTE-5 and EFOP-3.6.3VEKOP-16-2017-00008 projects. 


\section{References}

[1] Slavov, A. K. "General Characteristics and Treatment Possibilities of Dairy Wastewater - A Review", Food Technology and Biotechnology, 55(1), pp. 14-28, 2017. https://doi.org/10.17113/ftb.55.01.17.4520

[2] Vourch, M., Balannec, B., Chaufer, B., Dorange, G. "Treatment of dairy industry wastewater by reverse osmosis for water reuse", Desalination, 219(1-3), pp. 190-202, 2008. https://doi.org/10.1016/j.desal.2007.05.013

[3] Sarkar, B., Chakrabarti, P. P., Vijaykumar, A., Kale, V. "Wastewater treatment in dairy industries: possibility of reuse", Desalination, 195(1-3), pp. 141-152, 2006.

https://doi.org/10.1016/j.desal.2005.11.015

[4] Andrade, L. H., Motta, G. E., Amaral, M. C. S. "Treatment of dairy wastewater with a membrane bioreactor", Brazilian Journal of Chemical Engineering, 30(4), pp. 759-770, 2013.

https://doi.org/10.1590/S0104-66322013000400008

[5] Bortoluzzi, A. C., Faitão, J. A., Di Luccio, M., Dallago, R. M., Steffens, J., Zabot, G. L., Tres, M. V. "Dairy wastewater treatment using integrated membrane systems", Journal of Environmental Chemical Engineering, 5(5), 4819-4827, 2017.

https://doi.org/10.1016/j.jece.2017.09.018

[6] Ng, K. S. Y., Haribabu, M., Harvie, D. J. E., Dunstan, D. E., Martin, G. J. O. "Mechanism of flux decline in skim milk ultrafiltration: A review", Journal of Membrane Science, 523, pp. 144-162, 2017

https://doi.org/10.1016/j.memsci.2016.09.036

[7] Vrijenhoek, E. M., Hong, S., Elimelech, M. "Influence of membrane surface properties on initial rate of colloidal fouling of reverse osmosis and nanofiltration membranes", Journal of Membrane Science, 188(1), pp. 115-128, 2001. https://doi.org/10.1016/S0376-7388(01)00376-3

[8] Ding, Y., Ma, B., Liu, H., Qu, J. "Effects of protein properties on ultrafiltration membrane fouling performance in water treatment", Journal of Environmental Sciences, 77, pp. 273-281, 2019. https://doi.org/10.1016/j.jes.2018.08.005

[9] Walstra, P., Wouters, J. T. M., Geurts, T. J. "Dairy Science and Technology", CRC Press, Boca Raton, FL, USA, 2005. https://doi.org/10.1201/9781420028010

[10] Brule, G., Real del Sol, E., Fauquant, J., Fiaud, C. "Mineral Salts Stability in Aqueous Phase of Milk: Influence of Heat Treatments", Journal of Dairy Science, 61(9), pp. 1225-1232, 1978. https://doi.org/10.3168/jds.S0022-0302(78)83710-2

[11] Charley, P., Saltman, P. "Chelation of Calcium by Lactose: Its Role in Transport Mechanisms", Science, 139(3560), pp. 1205-1206, 1963. https://doi.org/10.1126/science.139.3560.1205

[12] Velpula, S., Umapathy, K. S., Thyarla, A., Srikanth, K., Saraff, S. "Dairy Wastewater Treatment by Membrane Systems A Review", International Journal of Pure \& Applied Bioscience, 5(6), pp. 389-395, 2017. https://doi.org/10.18782/2320-7051.5540

[13] Hashlamon, A., Mohammad, A. W., Ahmad, A. "The effect of wastewater pretreatment on nanofiltration membrane performance", Journal of Water Reuse and Desalination, 7(1), pp. 45-52, 2017. https://doi.org/10.2166/wrd.2016.083
[14] De Angelis, L., Fidalgo de Cortalezzi, M. M. "Improved membrane flux recovery by Fenton-type reactions", Journal of Membrane Science, 500, pp. 255-264, 2016. https://doi.org/10.1016/j.memsci.2015.11.042

[15] Cañizares, P., Paz, R., Sáez, C., Rodrigo, M. A. "Costs of the electrochemical oxidation of wastewaters: A comparison with ozonation and Fenton oxidation processes", Journal of Environmental Management, 90(1), pp. 410-420, 2009. https://doi.org/10.1016/j.jenvman.2007.10.010

[16] Hartmann, M., Kullmann, S., Keller, H. "Wastewater treatment with heterogeneous Fenton-type catalysts based on porous materials", Journal of Materials Chemistry 20(41), pp. 9002-9017, 2010. https://doi.org/10.1039/C0JM00577K

[17] Babuponnusami, A., Muthukumar, K. "A review on Fenton and improvements to the Fenton process for wastewater treatment", Journal of Environmental Chemical Engineering, 2(1), pp. 557-572, 2014. https://doi.org/10.1016/j.jece.2013.10.011

[18] Zhu, H. T., Wen, X. H., Huang, X. "Pre-ozonation for dead-end microfiltration of the secondary effluent: suspended particles and membrane fouling", Desalination, 231(1-3), pp. 166-174, 2008. https://doi.org/10.1016/j.desal.2007.11.044

[19] Chen, F., Shi, X., Chen, X., Chen, W. "An iron (II) phthalocyanine/poly(vinylidene fluoride) composite membrane with antifouling property and catalytic self-cleaning function for high-efficiency oil/water separation", Journal of Membrane Science, 552, pp. 295-304, 2018.

https://doi.org/10.1016/j.memsci.2018.02.030

[20] László, Z., Kertész, S., Beszédes, S., Hovorka-Horváth, Z., Szabó, G., Hodúr, C. "Effect of preozonation on the filterability of model dairy waste water in nanofiltration", Desalination, 240(1-3), pp. 170-177, 2009. https://doi.org/10.1016/j.desal.2007.12.040

[21] Van Geluwe, S., Braeken, L., Van der Bruggen, B. "Ozone oxidation for the alleviation of membrane fouling by natural organic matter: A review", Water Researh, 45(12), pp. 3551-3570, 2011. https://doi.org/10.1016/j.watres.2011.04.016

[22] Kiss, Z. L., Kocsis, L., Keszthelyi-Szabó, G., Hodúr, C., László, Z. "Treatment of oily wastewater by combining ozonation and microfiltration", Desalination and Water Treatment, 55(13), pp. 3662-3669, 2015. https://doi.org/10.1080/19443994.2014.939877

[23] Nguyen, S. T., Roddick, F. A. "Pre-treatments for removing colour from secondary effluent: Effectiveness and influence on membrane fouling in subsequent microfiltration", Separation and Purification Technology, 103, pp. 313-320, 2013. https://doi.org/10.1016/j.seppur.2012.10.011

[24] László, Z., Kertész, S., Mlinkovics, E., Hodúr, C. "Dairy Waste Water Treatment by Combining Ozonation and Nanofiltration", Separation Science and Technology, 42(7), 1627-1637, 2007. https://doi.org/10.1080/01496390701290508 
[25] Vela, M. C. V., Álvarez Blanco, S., García, J. L., Bergantiños Rodríguez, E. "Analysis of membrane pore blocking models applied to the ultrafiltration of PEG", Separation and Purification Technology, 62(3), pp. 489-498, 2008.

https://doi.org/10.1016/j.seppur.2008.02.028

[26] Zakar, M., Kovács, I., Muhi, P., Hanczné Lakatos, E., KeszthelyiSzabó, G., László, Zs. "The Effect of Advanced Oxidation Pretreatment on the Membrane Filtration Parameters of Dairy Wastewater", Hungarian Journal of Industry and Chemistry, 45(2), pp. 23-27, 2017.

https://doi.org/10.1515/hjic-2017-0016
[27] Choo, K. H., Lee, C. H. "Understanding Membrane Fouling in Terms of Surface Free Energy Changes", Journal of Colloid and Interface Science, 226(2), pp. 367-370, 2000.

https://doi.org/10.1006/jcis.2000.6845 